\title{
Effect of Recombinant Human Endostatin Injection Combined with Chemotherapy on Non-Small Cell Lung Cancer and Activated Circulating Endothelial Cells
}

\author{
JI MIN DONG, WU HONG ZHENG ${ }^{1}$, XIANG FEI SUN, JIAN YING LI ${ }^{2}$, BEI BEI WAN² AND ZHANG MIN YANG ${ }^{4 *}$
}

Department of Oncology, Xi'an Central Hospital, Xi'an, Shaanxi 710003, 'Department of Respiratory Medicine, Shaanxi Aerospace Hospital, Xi'an, Shaanxi 710000, ${ }^{2}$ Department of Respiratory Medicine, ${ }^{3}$ Department of Radiology, Xi'an Central Hospital, Xi'an, Shaanxi 710003, ${ }^{4}$ Department of Biochemistry and Molecular Biology, College of Life Sciences, Shaanxi Normal University, Xi'an, Shaanxi 710119, China

Dong et al.: Effect of Recombinant Human Endostatin Injection Combined with Chemotherapy

\begin{abstract}
To explore the clinical efficacy of recombinant human endostatin injection combined with chemotherapy in the treatment of non-small cell lung cancer and the influence on activated circulating endothelial cells in peripheral blood. A total of 100 non-small cell lung cancer patients were selected and divided into combination and chemotherapy group. Another 30 healthy volunteers were selected as healthy control group. The shortterm treatment effects, drug side effects during treatment and long-term quality of life were compared. Enzyme-linked immunosorbent assay was used to detect the levels of vascular endothelial growth factor and basic fibroblast growth factor. Flow cytometry was used to detect the expression of CD105 and CD146. The total effective rate, leukopenia, thrombocytopenia, nausea/vomiting, peripheral neurotoxicity, cardiac injury and fever were significantly different between the two groups $(\mathbf{p}<0.05)$. The physical role, emotional, social and general health scores were significantly higher, and the fatigue, nausea and vomiting, pain, shortness of breath, loss of appetite, constipation, lung cancer specific modules and total symptom subscale score were significantly lower in combination group than those in chemotherapy group $(\mathbf{p}<\mathbf{0 . 0 5})$. The levels of vascular endothelial growth factor and basic fibroblast growth factor in combination group were decreased and activated circulating endothelial cells were increased after treatment, while in the chemotherapy group, activated circulating endothelial cells only increased in the $4^{\text {th }}$ cycle $(p<0.05)$. Endo combined with chemotherapy has a significant short-term effect in the treatment of non-small cell lung cancer, which can reduce side effects and improve the quality of life.
\end{abstract}

Key words: Non-small cell lung cancer, endostatin injection, vascular endothelial growth factor, activated circulating endothelial cells

Lung cancer is currently the malignant tumor with leading mortality clinically. More than $85 \%$ of lung cancer patients belong to Non-Small Cell Lung Cancer (NSCLC). When NSCLC patients are in the advanced stages, they are no longer suitable for surgical treatment, so the curative chemotherapy is the most effective way to prolong the survival of patients ${ }^{[1]}$. Anti-angiogenic drugs are anti-cancer drugs used in combination with chemotherapeutic drugs in recent years. They mainly achieve tumor cell necrosis by reducing vascular permeability and changing perfusion, among which, Recombinant Human Endostatin Injection (Endo) is more common ${ }^{[2]}$. Anti-angiogenesis combined with chemotherapy can significantly prolong the progressionfree survival and overall survival of NSCLC, which is widely used in clinical practice. However, the characteristic of such drugs is to inhibit tumor growth, rather than directly shrinking tumors. In the evaluation system based on tumor volume changes, their effects are often underestimated. Therefore, finding effective evaluation markers has become an important research direction. The main targets of anti-angiogenic drugs are Circulating Endothelial Cells (CECs). Beaudry et al. has confirmed that the change of CECs in tumorbearing animals is significantly related to the antitumor effect of angiostatin ${ }^{[3]}$. The main sources of CECs include circulating endothelial precursor cells in the bone marrow and Activated Circulating Endothelial Cells (aCECs) on the surrounding blood vessel walls. Its changes reflect the final results of the mutual

*Address for correspondence

E-mail: yzhangmin@yahoo.com 
antagonism of anti-vascular and pro-angiogenic factors and may become an effective marker for evaluating anti-angiogenesis ${ }^{[4]}$.

There are various cytokines involved in the process of angiogenesis, among which Vascular Endothelial Growth Factor (VEGF) and Basic Fibroblast Growth Factor (bFGF) are the most important. The formation of tumor blood vessels has a certain degree of tissue invasiveness. Tumor cells can invade outward along the gaps between tissues opened by newly formed blood vessels, thereby further eroding the surrounding tissues. VEGF secreted by tumor cells can increase the permeability of blood vessels and promote the exudation of macromolecular substances, which is beneficial to the formation of metastatic tumor stroma. It can be seen that if the growth of tumor new blood vessels can be inhibited, it is possible to limit the tumor growth and eventually the tumor can be cured. Studies have shown that endostatin shows a potent activity in inhibiting tumor angiogenesis in the body and does not produce drug resistance ${ }^{[5-7]}$. Therefore, this study explored the effect of Endo combined with chemotherapy on the treatment of NSCLC and influence on aCECs.

\section{MATERIALS AND METHODS}

\section{General data:}

Inclusion criteria-Patients with locally advanced or metastatic NSCLC confirmed by histology or cytology, without chemotherapy treatment or with only firstline treatment. Other conditions: Single diameter of the lesion $\geq 1 \mathrm{~cm}$; physical condition score, that is Eastern Cooperative Oncology Group (ECOG) $\leq 2$ points; estimated survival time $\geq 3 \mathrm{mo}$; no history of allergies to drugs such as biological agents, etc.; patients voluntarily participated and signed informed consent. Exclusion criteria: Uncontrolled acute infection or brain metastasis; history of severe heart disease; obvious bleeding tendency; past application of Endo treatment, etc. A total of 100 NSCLC patients admitted to our hospital from January 2019 to January 2021 were selected and all diagnosed and confirmed by histopathology or cytology. According to the random number table, they were divided into a combination group and a chemotherapy group, with 50 cases in each group. In the combination group, there were 38 males and 12 females; they were 41-79 y old, with an average age of $64.2 \pm 7.5 \mathrm{y}$; there were 26 cases of adenocarcinoma and 24 cases of squamous cell carcinoma; there were 20 cases at stage IIIB and 30 cases at stage IV. In the chemotherapy group, there were 40 males and 10 females; they were $42-78$ y old, with an average age of $63.9 \pm 8.1 \mathrm{y}$; there were 27 cases of adenocarcinoma and 23 cases of squamous cell carcinoma; there were 21 cases at stage IIIB and 29 cases at stage IV. There was no statistically significant difference in general data between the two groups $(p>0.05)$. Another 30 healthy volunteers were selected as the healthy control group and only their peripheral blood was collected for CECs examination without treatment. This study was approved by the ethics committee of our hospital.

\section{Treatment methods:}

Chemotherapy group: TP regimen alone for treatment. Paclitaxel $135 \mathrm{mg} / \mathrm{m}^{2}$, intravenous drop infusion on the $1^{\text {st }} \mathrm{d} ; 10 \mathrm{mg}$ of dexamethasone was taken orally at 21:00 $1 \mathrm{~d}$ before intravenous drop infusion of paclitaxel and at 03:00 on the same day; cisplatin $75 \mathrm{mg} / \mathrm{m}^{2}$, intravenous drop infusion on the $1^{\text {st }}$ d. Every $3 \mathrm{w}$ was a treatment cycle with $1 \mathrm{w}$ rest. There were at least 4 cycles of chemotherapy.

Combination group: Endo combined with TP regimen for treatment and the TP regimen was the same as the chemotherapy group. Endo (Shandong Simcere Medical Biopharmaceutical Co., Ltd., $15 \mathrm{mg} / 3 \mathrm{ml} /$ bottle) was administrated at $15 \mathrm{mg} /$ time, 1 time $/ \mathrm{d}$ with continuous administration for $14 \mathrm{~d}$.

\section{Flow cytometry to detect aCECs:}

A total of $1 \mathrm{ml}$ of venous blood was taken within 3 $\mathrm{d}$ before treatment and within $3 \mathrm{~d}$ after each cycle of treatment, and flow cytometry was used to detect the serum aCECs level and baseline range of the subjects.

Each $0.1 \mathrm{ml}$ of anticoagulated whole blood was taken and added to the experimental tube and the isotype control tube. The $10 \mu \mathrm{l}$ of Fluorescein Isothiocyanate (FITC)-labeled mouse anti-human Endoglin (CD105), $10 \mu$ of Phycoerythrin (PE)-labeled mouse anti-human CD146 and $10 \mu$ of PE-Cy5-labeled mouse anti-human CD45 was added to the study tube and the $10 \mu 1$ of FITClabeled mouse Immunoglobulin G1 (IgG1), $10 \mu$ of PElabeled mouse IgG1, $10 \mu \mathrm{l}$ of PE-Cy5-labeled mouse IgG2a was added to the control tube, respectively, with incubation in the dark for 30 to $45 \mathrm{~min}$. All reagents were purchased from Beckman Coulter, USA.

The $0.5 \mathrm{ml}$ of red blood cell lysis solution, Opti-Lyse C, was added to each of the above tubes, incubated for 15 min and added with Phosphate Buffered Saline (PBS) for routine washing. The supernatant was discarded after centrifugation, added with $0.5 \mathrm{ml}$ of sheath solution and shaked, and mixed for testing.

Standard fluorescent microspheres were used to 
routinely calibrate the variation coefficient of the instrument and stabilize it within 2. The logic gating method was used to determine the target cells and 100000 cells were collected. The expression rate was determined based on the fluorescence emitted by the cells and the number of CD45-CD105+ CD146+ cells was calculated ${ }^{[8,9]}$.

The change difference of aCECs was calculated: Difference value $=$ Value after treatment-Value before treatment.

\section{Observation indexes:}

The World Health Organization (WHO) short-term efficacy evaluation standard for solid tumors was used for efficacy evaluation, which was divided into Complete Response (CR), Partial Response (PR), No Change (NC) or stable and Progressive Disease (PD). Clinical Response Rate $(\mathrm{RR})=(\mathrm{CR}+\mathrm{PR})$ cases/total cases $\times 100 \%$.

The Enzyme-Linked Immunosorbent Assay (ELISA) method was used to detect the levels of VEGF and bFGF in the serum of the enrolled patients before treatment and $7 \mathrm{~d}, 14 \mathrm{~d}$, and $21 \mathrm{~d}$ after treatment.

The evaluation of Quality of Life (QOL) referred to the cancer-specific Quality of Life Questionnaire Scale (QLQ-C30) ${ }^{[10]}$, including two parts of the general health and the symptom subscale. The higher the general health score and the lower the symptom subscale score, the higher the QOL.

The change in the number of CECs was determined in each cycle of treatment.

\section{Statistical analysis:}

The statistical software Statistical Package for the Social Sciences (SPSS) 18.0 was used for statistical processing and analysis. The measurement data were expressed as mean \pm standard Deviation (SD) using $t$ test and the count data was expressed by the number of cases and percentages using $\chi^{2}$ test, $p<0.05$ was statistically significant.

\section{RESULTS AND DISCUSSION}

Clinical efficacy between the two groups was compared. After all patients completed 4 cycles of chemotherapy, the clinical effective rate in the combination group was significantly higher than that in the chemotherapy group ( $\mathrm{p}<0.05)$, as shown in Table 1 .

Serum levels of VEGF and bFGF before and after treatment between the two groups were compared.
The serum levels of VEGF and bFGF of patients in the combination group decreased after treatment compared with those before treatment and the difference was statistically significant $(\mathrm{p}<0.05)$; the serum levels of VEGF and bFGF of patients in the chemotherapy group decreased after treatment compared with those before treatment, but the difference was not statistically significant ( $\mathrm{p}>0.05)$, as shown in Table 2 .

Changes in aCECs after treatment between the two groups were compared. The baseline range in the healthy control group was $(45,12-215) / 10^{5}$ cells, lymph node (ln) aCECs $(1.7 \pm 0.3)$; the baseline range in the chemotherapy group was $(67,25-335) / 10^{5}$ cells, $1 n$ aCECs (4.4 \pm 1.7$)$; the baseline range in the combination group was $(75,35-390) / 10^{5}$ cells, $\ln$ aCECs $(4.7 \pm 1.5)$, as shown in Table 3.

Changes of aCECs in the chemotherapy group after treatment were shown here. In the 1, 2, 3 and 4 cycles after treatment, aCECs were $(105,65-404) / 10^{5}$ cells, ln aCECs $(4.5 \pm 1.8) ;(175,125-470) / 10^{5}$ cells, In aCECs $(5.0 \pm 1.5)$; $(254,205-714) / 10^{5}$ cells, ln aCECs (5.2 \pm 1.9$)$; and $(110,150-480) / 10^{5}$ cells, In aCECs (4.8 1.9$)$. Among them, the value of the third cycle was significantly higher than that of the baseline $(\mathrm{p}=0.040)$.

Changes in aCECs in the combination group after treatment were shown here. In 1, 2, 3, and 4 cycles after treatment, aCECs were: $(46,9-522) / 10^{5}$ cells, $1 n$ aCECs (4.6 \pm 1.2$) ;(126,62-256) / 10^{5}$ cells, $1 n$ aCECs $(5.2 \pm 1.3)$; (100.44-131.3)/10 cells, $\ln$ aCECs ( $5.3 \pm 1.3)$; and (180, 68-744) $/ 10^{5}$ cells, In aCECs $(5.5 \pm 1.1)$. After treatment, aCECs were significantly higher than the baseline $(\mathrm{p}<0.05)$.

Occurrence of adverse reactions between the two groups was compared. The differences in leukopenia, thrombocytopenia, nausea/vomiting, peripheral neurotoxicity, heart injury and fever between the two groups were statistically significant (all $\mathrm{p}<0.05$ ), as shown in Table 4.

QOL scores between the two groups were compared. The physical role, emotional, social and general health scores in the combination group were significantly higher than those in the chemotherapy group after treatment $(\mathrm{t} \geq 4.475$, all $\mathrm{p}<0.05)$; fatigue, nausea and vomiting, pain, shortness of breath, loss of appetite, constipation, lung cancer specific modules and total symptom subscale score in the combination group were significantly lower than those in the chemotherapy group after treatment $(\mathrm{t} \geq 4.807$, all $\mathrm{p}<0.05)$, as shown in Table 5. 
TABLE 1: CLINICAL EFFICACY OF THE TWO GROUPS OF PATIENTS

\begin{tabular}{lccccc}
\hline Groups & CR & PR & NC & PD & Total effective rate \\
\hline $\begin{array}{l}\text { Chemotherapy } \\
\text { group }\end{array}$ & 0 & $24(48.00)$ & $19(38.00)$ & $7(14.00)$ & $86.00 \%$ \\
Combination group & 0 & $18(36.00)$ & $17(34.00)$ & $15(30.00)$ & $70.00 \%$ \\
\hline
\end{tabular}

TABLE 2: SERUM LEVELS OF VEGF AND BFGF BEFORE AND AFTER TREATMENT OF THE TWO GROUPS OF PATIENTS

\begin{tabular}{|c|c|c|c|c|c|}
\hline \multirow{2}{*}{\multicolumn{2}{|c|}{ Groups }} & \multicolumn{2}{|c|}{ VEGF* } & \multicolumn{2}{|c|}{ bFGF" } \\
\hline & \multicolumn{5}{|c|}{ Combination group $(n=50)$} \\
\hline Before treatment & & \multicolumn{2}{|c|}{$522.65 \pm 109.12$} & \multicolumn{2}{|c|}{$27.21 \pm 11.37$} \\
\hline $7 \mathrm{~d}$ after treatment & & \multicolumn{2}{|c|}{$325.81 \pm 92.63$} & \multicolumn{2}{|c|}{$18.52 \pm 10.04$} \\
\hline $14 \mathrm{~d}$ after treatment & & \multicolumn{2}{|c|}{$290.34 \pm 89.36$} & \multicolumn{2}{|c|}{$15.26 \pm 9.07$} \\
\hline $21 \mathrm{~d}$ after treatment & & \multicolumn{2}{|c|}{$258.35 \pm 77.52$} & \multicolumn{2}{|c|}{$13.02 \pm 8.86$} \\
\hline \multicolumn{6}{|c|}{ Chemotherapy group $(n=50)$} \\
\hline Before treatment & & \multicolumn{2}{|c|}{$502.97 \pm 102.63$} & \multicolumn{2}{|c|}{$28.32 \pm 11.94$} \\
\hline $7 \mathrm{~d}$ after treatment & & \multicolumn{2}{|c|}{$499.13 \pm 98.38$} & \multicolumn{2}{|c|}{$27.49 \pm 10.18$} \\
\hline $14 \mathrm{~d}$ after treatment & & \multicolumn{2}{|c|}{$481.62 \pm 112.06$} & \multicolumn{2}{|c|}{$26.71 \pm 9.03$} \\
\hline $21 \mathrm{~d}$ after treatment & & \multicolumn{2}{|c|}{$488.41 \pm 100.73$} & \multicolumn{2}{|c|}{$28.35 \pm 9.47$} \\
\hline \multicolumn{6}{|c|}{$\begin{array}{l}\text { Note: }{ }^{*} \text { indicates } F \text { group-12.404; F time-617.838; F interaction-480.212, all } p<0.001 ; \text {;indicates } F \text { group-4.838; F time-120.542; F } \\
\text { interaction-101.514, all } p<0.001\end{array}$} \\
\hline Groups & $\begin{array}{l}\text { Before treatment } \\
\qquad\left(10^{5}\right)\end{array}$ & $\begin{array}{l}\text { Treatment for } 1 \\
\quad \text { cycle }\left(10^{5}\right)\end{array}$ & $\begin{array}{l}\text { Treatment for } 2 \\
\text { cycles }\left(10^{5}\right)\end{array}$ & $\begin{array}{l}\text { Treatment for } 3 \\
\text { cycles }\left(10^{5}\right)\end{array}$ & $\begin{array}{l}\text { Treatment for } 4 \\
\text { cycles }\left(10^{5}\right)\end{array}$ \\
\hline $\begin{array}{l}\text { Combination group } \\
(\mathrm{n}=50)\end{array}$ & $4.7 \pm 1.5$ & $4.6 \pm 1.2$ & $5.2 \pm 1.3$ & $5.3 \pm 1.3$ & $5.5 \pm 1.1$ \\
\hline $\begin{array}{l}\text { Chemotherapy } \\
\text { group }(n=50)\end{array}$ & $4.4 \pm 1.7$ & $4.5 \pm 1.8$ & $5.0 \pm 1.5$ & $5.2 \pm 1.9$ & $4.8 \pm 1.9$ \\
\hline $\begin{array}{l}\text { Healthy control } \\
\text { group }(n=50)\end{array}$ & $1.7 \pm 0.3$ & - & - & - & - \\
\hline
\end{tabular}

TABLE 4: OCCURRENCE OF ADVERSE REACTIONS OF THE TWO GROUPS OF PATIENTS

\begin{tabular}{|c|c|c|c|c|c|c|c|c|c|c|}
\hline \multirow{2}{*}{ Groups } & \multicolumn{4}{|c|}{ Combination group $(n=50)$} & \multicolumn{4}{|c|}{ Chemotherapy group $(n=50)$} & \multirow{2}{*}{$t$} & \multirow{2}{*}{$p$} \\
\hline & 0 & I & II & III/IV & 0 & I & II & III/IV & & \\
\hline Leukopenia & 17 & 20 & 10 & 3 & 8 & 16 & 16 & 10 & 2.928 & 0.003 \\
\hline Thrombocytopenia & 14 & 19 & 15 & 2 & 5 & 12 & 26 & 7 & 3.376 & 0.001 \\
\hline Nausea/vomiting & 13 & 22 & 11 & 4 & 10 & 12 & 20 & 8 & 2.138 & 0.033 \\
\hline $\begin{array}{l}\text { Peripheral } \\
\text { neurotoxicity }\end{array}$ & 18 & 21 & 10 & 1 & 11 & 16 & 17 & 6 & 2.536 & 0.011 \\
\hline Heart injury & 23 & 16 & 11 & 0 & 16 & 11 & 22 & 1 & 2.228 & 0.026 \\
\hline Liver injury & 15 & 28 & 7 & 0 & 10 & 28 & 12 & 0 & 1.501 & 0.134 \\
\hline Kidney injury & 41 & 9 & 0 & 0 & 33 & 15 & 2 & 0 & 1.890 & 0.059 \\
\hline Fever & 25 & 24 & 1 & 0 & 16 & 30 & 4 & 0 & 2.022 & 0.044 \\
\hline Alopecia & 43 & 7 & 0 & 0 & 38 & 12 & 0 & 0 & 1.268 & 0.207 \\
\hline Rash & 44 & 6 & 0 & 0 & 37 & 13 & 0 & 0 & 1.775 & 0.077 \\
\hline
\end{tabular}


www.ijpsonline.com

TABLE 5: LONG-TERM QOL SCORE OF THE TWO GROUPS OF PATIENTS

\begin{tabular}{|c|c|c|c|c|}
\hline \multirow{2}{*}{ Groups } & \multicolumn{2}{|c|}{ Combination group $(n=50)$} & \multicolumn{2}{|c|}{ Chemotherapy group $(n=50)$} \\
\hline & Before treatment & After treatment & Before treatment & After treatment \\
\hline Physical domain & $89.02 \pm 5.06$ & $82.44 \pm 4.75$ & $89.15 \pm 5.28$ & $70.06 \pm 4.96$ \\
\hline Role domain & $37.40 \pm 10.21$ & $67.84 \pm 9.34$ & $37.63 \pm 11.55$ & $50.32 \pm 10.07$ \\
\hline Emotional domain & $64.32 \pm 9.66$ & $91.50 \pm 11.59$ & $64.70 \pm 9.78$ & $76.54 \pm 10.87$ \\
\hline Cognitive domain & $80.87 \pm 17.56$ & $78.83 \pm 16.46$ & $79.56 \pm 16.33$ & $77.60 \pm 16.63$ \\
\hline Social domain & $57.81 \pm 8.08$ & $67.31 \pm 8.95$ & $57.42 \pm 8.14$ & $59.52 \pm 8.45$ \\
\hline General domain & $65.32 \pm 7.17$ & $77.05 \pm 9.50$ & $65.09 \pm 7.28$ & $66.40 \pm 8.96$ \\
\hline $\begin{array}{l}\text { Total symptom subscale } \\
\text { score }\end{array}$ & $197.46 \pm 48.96$ & $204.52 \pm 52.68$ & $196.70 \pm 45.31$ & $271.72 \pm 58.30$ \\
\hline Fatigue & $12.64 \pm 7.82$ & $20.03 \pm 5.63$ & $12.81 \pm 7.59$ & $35.04 \pm 7.51$ \\
\hline Nausea and vomiting & $4.05 \pm 0.87$ & $17.52 \pm 46.30$ & $4.12 \pm 1.05$ & $23.84 \pm 6.70$ \\
\hline Pain & $10.45 \pm 5.16$ & $17.90 \pm 7.80$ & $10.38 \pm 5.69$ & $30.70 \pm 8.09$ \\
\hline Shortness of breath & $15.3 \pm 4.88$ & $25.44 \pm 7.45$ & $15.72 \pm 5.06$ & $37.84 \pm 8.57$ \\
\hline Insomnia & $18.4 \pm 5.36$ & $30.24 \pm 9.12$ & $18.15 \pm 6.82$ & $29.84 \pm 10.27$ \\
\hline Loss of appetite & $27.21 \pm 7.82$ & $5.40 \pm 1.45$ & $27.09 \pm 10.21$ & $14.05 \pm 4.82$ \\
\hline Constipation & $16.21 \pm 5.77$ & $3.30 \pm 0.97$ & $16.42 \pm 5.68$ & $7.67 \pm 1.58$ \\
\hline Diarrhea & $0.45 \pm 0.27$ & $1.33 \pm 0.80$ & $0.40 \pm 0.31$ & $1.41 \pm 0.69$ \\
\hline Economic difficulties & $33.4 \pm 12.65$ & $33.52 \pm 13.55$ & $33.59 \pm 11.60$ & $32.54 \pm 14.20$ \\
\hline $\begin{array}{l}\text { Lung cancer specific } \\
\text { modules }\end{array}$ & $55.83 \pm 9.10$ & $45.53 \pm 7.45$ & $55.45 \pm 8.76$ & $52.62 \pm 7.30$ \\
\hline
\end{tabular}

Tumor epidemiology reveals that the incidence of lung cancer ranks first among malignant tumors and 75 $\%-80 \%$ of lung cancer patients are with NSCLC ${ }^{[11]}$. New angiogenesis is of great significance to the growth, invasion and metastasis of tumor tissues ${ }^{[12,13]}$. Endo itself does not have a cytotoxic effect, so it is difficult to shrink tumors quickly, but it may inhibit tumor angiogenesis by downregulating the expression of angiogenesispromoting factors in tumor tissues and inhibiting their activity, thereby hindering tumor growth ${ }^{[14]}$. In addition, anti-angiogenic drugs and chemotherapy have a synergistic effect and the ways and methods of action are as follows ${ }^{[15]}$ : Anti-angiogenic drugs helps to normalize the chaotic and tortuous blood vessels in tumor tissues, so that chemotherapeutic drugs can enter better inside the tumors, thereby killing the tumor tissues. Antiangiogenic drugs can induce apoptosis of endothelial cells and inhibit angiogenesis, thereby suppressing tumor growth and metastasis. Anti-angiogenic drugs can inhibit the activity of Matrix Metalloproteinases (MMPs), interfere with the actions such as the binding of VEGF and receptors, etc., and block the molecular signaling pathways of angiogenesis, which makes micrometastases in a dormant state, thereby reducing the possibility of tumor metastasis and recurrence.

Among the known angiogenesis-promoting factors,
VEGF and bFGF are the most closely related with tumor angiogenesis and there is a synergistic effect between the two. VEGF is the most important tumor angiogenesis-promoting factor discovered so $\mathrm{far}^{[16]}$. The results of the study showed that the serum levels of VEGF and bFGF of patients in the combination group decreased after treatment compared with those before treatment, and the difference was statistically significant $(p<0.05)$; the serum levels of VEGF and bFGF of patients in the chemotherapy group decreased after treatment compared with those before treatment, but the difference was not statistically significant $(\mathrm{p}>0.05)$, indicating that Endo may inhibit the production of VEGF and bFGF in tumor cells, thereby reducing the serum levels of VEGF and bFGF.

The dynamic changes of aCECs have always been controversial. Beaudry et al. have studied the Vascular Endothelial Growth Factor Receptor(VEGFR) inhibitor, ZD6474 and found that ZD6474 can increase CECs while reduce microvessel density and tumor size ${ }^{[3]}$. Li et al. have found that after thalidomide combined with docetaxel treatment, both apoptotic CECs and aCECs in prostate cancer showed an increasing trend ${ }^{[17]}$. Kawaishi et al. has observed the decrease in aCECs on the $8^{\text {th }}$ and $22^{\text {nd }} \mathrm{d}$ of lung cancer patients after treatment with paclitaxel combined with carboplatin ${ }^{[18]}$. The research 
has observed a significant decrease in the number of aCECs in effective cases of chemotherapy combined with Endo in the treatment of NSCLC ${ }^{[2]}$. Therefore, in the process of effective anti-angiogenesis combined chemotherapy, aCECs should show a number trend of "rising first and then falling". First of all, Endo inhibits MMPs, which reduces the degradation of tumor vascular basement membrane, vascular permeability and local tissue interstitial fluid pressure and causes expanded blood vessels to contract and endothelial cells on the inner wall of blood vessels to be "squeezed out" in the blood circulation, resulting in increase in the number of aCECs. Subsequently, cytotoxic drugs induce apoptosis of aCECs and as the tumor size decreases, Tumor Angiogenesis Factors (TAFs) and aCECs becomes fewer and fewer. Therefore, the initial increase of aCECs reflects the shrinkage of the tumor vascular bed area and the final decrease indicates the apoptosis of CECs and the weakening of tumor angiogenesis. In this study, the aCECs in the chemotherapy group and the combination group were both raised and lowered, indicating that CECs were always in a dynamic rising and falling state during treatment. It was the "vascular normalization" that caused their rise and induction of apoptosis, which led to their dynamic balance performance ${ }^{[19]}$. A study has revealed that the effect of "vascular normalization" only appears in 1 to $2 \mathrm{w}$ after anti-angiogenesis treatment, which is transient and then it is transferred to inhibit tumor blood vessels, which leads to its shrinkage and "vascular deficiency"[20]. This study demonstrated that due to multiple and periodic medications in treatment, the two effects should alternately coexist and the aCECs of effective cases in treatment also show repeated fluctuations in the decline. With the extension of treatment, the biological activity of tumor cells continues to decrease and TAFs decrease, and the area of intratumoral vascular bed and CECs will eventually show a significant decrease and stabilize.

As an anti-angiogenic drug, Endo can act on targets such as VEGF receptors, etc., to inhibit signal transduction and directly and indirectly regulate the survival of tumor cells. In addition, Endo has a higher bioconcentration after entering the human body, especially in lung tissues, where it has a higher effective bioconcentration. At the same time, the drug has the advantages of long half-life, higher anti-tumor activity, etc. Endo has a good inhibitory effect on a variety of tumor biological targets, thereby suppressing the activation of the signaling pathways, decreasing the incidence of cancer cell proliferation or drug resistance and at the same time, Endo can also hinder cancer cell invasion by inhibiting tyrosine kinase, thereby enhancing the therapeutic effect of chemotherapeutic drugs, reducing their usage and suppressing their side effects on the human body. The results of this study showed that the total effective rate in the combination group is higher than that in the chemotherapy group; the incidence of nausea/vomiting, peripheral neurotoxicity, heart injury, fever, leukopenia and thrombocytopenia in the combination group is lower than that in the chemotherapy group. The QOL score in the observation group after treatment was significantly higher than that in the chemotherapy group. This showed that Endo can significantly promote the short-term treatment effect and improve the side effects of chemotherapy, thereby increasing the patient's long-term QOL.

\section{Acknowledgements:}

This study was supported by Natural Science Foundation of Shaanxi Province (No. 2016SF-318).

\section{Conflict of interests:}

The author reported that there is no conflict of interest.

\section{REFERENCES}

1. MacDonald N, Shivers W, Narum D, Plum S, Wingard J, Fuhrmann S, et al. Endostatin binds tropomyosin: A potential modulator of the antitumor activity of endostatin. J Biol Chem 2001;276(27):25190-6.

2. Lee SJ, Jang JW, Kim YM, Lee HI, Jeon JY, Kwon YG, et al. Endostatin binds to the catalytic domain of matrix metalloproteinase-2. FEBS Lett 2002;519(1-3):147-52.

3. Beaudry P, Force J, Naumov GN, Wang A, Baker CH, Ryan $\mathrm{A}$, et al. Differential effects of vascular endothelial growth factor receptor-2 inhibitor ZD6474 on circulating endothelial progenitors and mature circulating endothelial cells: Implications for use as a surrogate marker of antiangiogenic activity. Clin Cancer Res 2005;11(9):3514-22.

4. Mancuso P, Bertolini F. Circulating endothelial cells as biomarkers in clinical oncology. Microvasc Res 2010;79(3):224-8.

5. Hanai JI, Gloy J, Karumanchi SA, Kale S, Tang J, Hu G, et al. Endostatin is a potential inhibitor of Wnt signaling. J Cell Biol 2002;158(3):529-39.

6. Scappaticci FA. Mechanisms and future directions for angiogenesis-based cancer therapies. J Clin Oncol 2002;20(18):3906-27.

7. Folkman J. Antiangiogenesis in cancer therapy-endostatin and its mechanisms of action. Exp Cell Res 2006;312(5):594-607.

8. Nagy K, Székely-Szüts K, Izeradjene K, Douglas L, Tillman M, Barti-Juhász H, et al. Proteasome inhibitors sensitize colon carcinoma cells to TRAIL-induced apoptosis via enhanced release of Smac/DIABLO from the mitochondria. Pathol Oncol Res 2006;12(3):133-42.

9. Ni Q, Ji H, Zhao Z, Fan X, Xu C. Endostar, a modified endostatin inhibits non-small cell lung cancer cell in vitro invasion through osteopontin-related mechanism. Eur J Pharmacol 2009;614(1-3):1-6. 
10. Fletcher JI, Haber M, Henderson MJ, Norris MD. ABC transporters in cancer: More than just drug efflux pumps. Nat Rev Cancer 2010;10(2):147-56.

11. Eichholz A, Merchant S, Gaya AM. Anti-angiogenesis therapies: Their potential in cancer management. Onco Targets Ther 2010;3:69-82.

12. Dienstmann R, Martinez P, Felip E. Personalizing therapy with targeted agents in non-small cell lung cancer. Oncotarget 2011;2(3):165-77.

13. Schettino C, A Bareschino M, Rossi A, Maione P, C Sacco $\mathrm{P}$, Colantuoni $\mathrm{G}$, et al. Targeting angiogenesis for treatment of NSCLC brain metastases. Curr Cancer Drug Targets 2012;12(3):289-99.

14. Liu SG, Yuan SH, Wu HY, Liu J, Huang CS. The clinical research of serum VEGF, TGF- $\beta 1$ and Endostatin in non-small cell lung cancer. Cell Biochem Biophys 2015;72(1):165-9.

15. Chen W, Zheng R, Baade PD, Zhang S, Zeng H, Bray F, et al. Cancer statistics in China, 2015. CA Cancer J Clin 2016;66(2):115-32.

16. Hu W, Fang J, Nie J, Dai L, Zhang J, Chen X, et al. Efficacy and safety of extended use of platinum-based doublet chemotherapy plus endostatin in patients with advanced nonsmall cell lung cancer. Medicine 2016;95(28):e4183.

17. Sia D, Villanueva A, Friedman SL, Llovet JM. Liver cancer cell of origin, molecular class, and effects on patient prognosis. Gastroenterology 2017;152(4):745-61.
18. Galsky MD, Arija JÁ, Bamias A, Davis ID, De Santis M, Kikuchi E, et al. Atezolizumab with or without chemotherapy in metastatic urothelial cancer (IMvigor130): A multicentre, randomised, placebo-controlled phase 3 trial. Lancet 2020;395(10236):1547-57.

19. Salerno M, Cenni E, Fotia C, Avnet S, Granchi D, Castelli $\mathrm{F}$, et al. Bone-targeted doxorubicin-loaded nanoparticles as a tool for the treatment of skeletal metastases. Curr Cancer Drug Targets 2010;10(7):649-59.

20. Xu M, Sheng LH, Zhu XH, Zeng SB, Zhang GJ. Reversal effect of Stephania tetrandra-Containing Chinese herb formula SENL on multidrug resistance in lung cancer cell line SW1573/2R120. Am J Chin Med 2010;38(02):401-13.

This is an open access article distributed under the terms of the Creative Commons Attribution-NonCommercial-ShareAlike 3.0 License, which allows others to remix, tweak, and build upon the work non-commercially, as long as the author is credited and the new creations are licensed under the identical terms

This article was originally published in a special issue, "Novel Therapeutic Approaches in Biomedicine and Pharmaceutical Sciences" Indian J Pharm Sci 2021:83(6) Spl Issue "151-157" 